\title{
Ultrasound enhancement of osmotic dehydration and drying - Process kinetics and quality aspects
}

Musielak, G.

Institute of Technology and Chemical Engineering. Poznań University of Technology, Poznań, Poland

E-mail of the corresponding author: grzegorz.musielak@put.poznan.pl

\begin{abstract}
The aim of presented studies is to investigate of influence of ultrasonic assistance on both osmotic dehydration and convective drying. A wide range of different materials, as well as several osmotic agents were tested.

The obtained results show that the use of ultrasound always accelerates the investigated processes. The application of ultrasound may reduce the energy consumption of drying. Qualitative studies of dried materials do not give a definite answer about the effect of ultrasound on the quality of the products. Mathematical modelling of the ultrasound assisted drying indicates that so named "vibration effect" plays the biggest role in convective drying acceleration.
\end{abstract}

Keywords: osmotic dehydration; convective drying; ultrasound; process kinetics. 


\section{Introduction}

Drying is one of the food preservation methods. The convective drying is the most commonly used technique. Unfortunately the method is slow and energy-consuming. Therefore, various methods to shorten the duration of the process and improve its energetical efficiency are investigated. One of the possibilities is the use of osmotic dehydratation as drying pretreatment. During the last two decades a great interest is directed to ultrasonic assistance of both osmotic dehydratation [1] and connective drying [1,2]. Also in the Department of Process Engineering, Poznan University of Technology, research in this area has been conducted for several years. The aim of this paper is to present a review of these research.

\section{Materials and methods}

\subsection{Tested materials}

A wide collection of various materials has been tested in the work of our team. Most of them are fruits and vegetables: apples [3-11], cherries [12], strawberries [9,13], raspberries [5,14], apricots [16] , carrots [9,17-21], green pepper [22], red pepper [11], potatoes [23], beetroot [24], onion [10]. In addition, kaolin was also tested [11,20].

\subsection{Osmotic dehydratation - method}

The simple osmotic dehydration and ultrasound assisted dehydratation (frequency $25 \mathrm{kHz}$ ) were tested to get the effect of ultrasound on the process kinetics and product quality. Aqueous solutions of glucose [12], fructose [6,17,19] and d-sorbitol [6] as working fluids were used. Kinetics and effectiveness of osmotic dehydratation were assessed on the basis of solid gain (SG), water loss (WL) and osmotic dehydratation rate (ODR):

$$
\mathrm{SG}=\frac{m_{s t}-m_{s i}}{m_{i}}, \quad W L=\frac{m_{i}-m_{t}}{m_{i}}+S G, \quad O D R=\frac{d m_{t}}{d t}
$$

where $m_{s t}, m_{s i}$ are masses of solid matter of osmotically dehydrated and fresh sample, respectively and $m_{i}, m_{t}$ are the initial and actual mass of sample, respectively.

\subsection{Drying - methods}

Several different dryers were used in the research. The laboratory chamber dryer was used for simple convective drying after osmotic dehydration [12,17]. Hybrid drying (convective microwave - radiative) after osmotic dehydratation was performed in prototype laboratory hybrid dryer [19]. All ultrasound assisted drying processes were carried out in one of two hybrid (convective - microwave - ultrasonic) laboratory dryers: cabinet dryer [3$5,7,8,10,11,13-16,18,20,22-24]$ and rotary dryer [6,9,21,24]. The influence of ultrasound assistance on convective drying [3-11,13-16,20-24] and on convective - microwave hybrid drying [11,13-16,18,19,21,22,24] was investigated. Continuous drying processes were studied in all papers, while in some works the intermitten drying was examined [2,11,12,15$17,20,24]$. The samples mass and their temperature were measured continuously during 
experiment. The moisture ratio $M R=\left(m_{t}-m_{e q}\right) /\left(m_{0}-m_{e q}\right)$ as a function of drying time represents drying kinetics, where $m_{t}, m_{0}$ and $m_{e q}$ are the instantaneous (for a given time of the process), initial and equilibrium sample mass, respectively.

Energy consumption was measured for the whole drying system with the electricity meter.

\subsection{Quality assesment - methods}

It is important to ensure the quality of the dried product. The basic parameters describing quality were: color change during drying (important from the consumer point of view) and water activity (responsible for durability of food).

The preservation of nutrients during the drying process is extremely important from the point of view of the food's value of the product. Retention of several nutrients were measured.

The dried product ability to irrigation was measured in rehydratation tests. Texture of dried apple was determined by compression tests with the acoustic emission measurement. Change of plant tissue microstructure (onion and apple) was observed.

\section{Experimental results}

\subsection{Osmotic dehydratation}

Osmotic dehydratation could be treated as predrying process. During simple osmotic dehydratation water loss (WL) ranged between 18\% [12] to 51\% [17] and solid gain (SG) ranged between $8 \%$ [17] to $12 \%$ [6,17]. The use of ultrasound to intensify the process caused WL increase by $14 \%$ [17] to $44 \%$ [19] and SG increase by $15 \%$ [17] to $45 \%$ [6]. It was also shown that osmotic dehydratation rate (ODR) increased [19].

After osmotic dehydratation, the samples were dried. Then the water activity and the color change of the samples were examined. The results of these tests indicate that the effect of ultrasound application on final water activity is negligible. The color change results are ambiguous. In works [12,17] a reduction in color change was obtained due to the use of ultrasound. On the other hand, the works $[6,19]$ indicate an increase of this parameter

\subsection{Drying}

\subsubsection{Drying kinetics and energetic effectiveness}

Drying kinetics is described by drying curves (moisture ratio $M R$ versus time) and temperature evolution. Figure 1 shows the results of convective drying (CV), convectivemicrowave drying (CVMV) and both methods ultrasound assisted (CVUS and CVUSMV, respectively). After the shortcut specifying the method (MV and US) the used power in watts was written. The use of ultrasounds during drying results in the process acceleration and in a slight increase in the temperature of the dried material. A clear acceleration in convective drying was obtained, while convective-microwave drying was only slightly accelerated. 
Ultrasonic assistance of convective drying shortened the drying process from $11 \%$ [5] to $60 \%$ [15]. This shortening of drying time resulted in a reduction of total energy consumption from $9 \%$ [3] to 21\% [14]. A slight acceleration of the convective-microwave drying process was associated with an increase in energy consumption.

a)

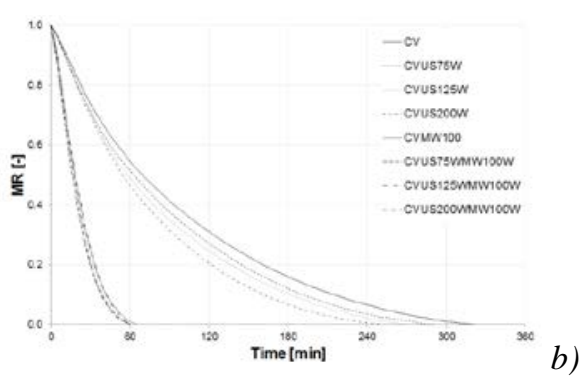

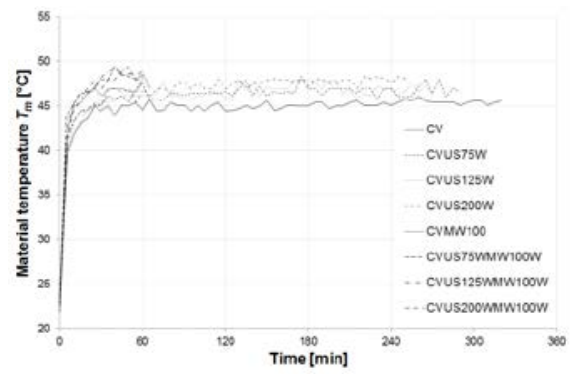

Fig. 1. Drying kinetics of carrots: a) drying curves; b) temperature of dried material [18]

\subsubsection{Products quality}

The use of ultrasound in each case resulted in a reduction in the color change. This reduction ranged between $12 \%[21,23]$ and $40 \%[13,18]$.

All studies indicate no impact of ultrasound on water activity. This parameter depends primarily on the final moisture content in the material, regardless of the drying method used.

Rehydratation ratio is defined as ratio of sample mass after rehydratation to initial sample mass (fresh material). Ultrasound application improved rehydratatin ratio from $14 \%$ [23] to $21 \%[16,22]$. This means that the use of ultrasound improves the internal structure.

The retention of vitamin $\mathrm{C}$ was improved due to ultrasound assistance (from $44 \%$ to $69 \%$ in green pepper [22] and from $68 \%$ to $70 \%$ in red pepper [11]). The obtained results regarding retention of phenolic compounds in carrot [18] are inconclusive. The use of ultrasound of low power caused a reduction in the phenolic compounds content while ultrasound of high power caused an increase in the content. The retention of carotenoids was improved due to ultrasound assistance (from 73,5\% to $90 \%$ in carrot [18] and from $67 \%$ to $76 \%$ in red pepper [11]). The retention of betanin in red beetroot was improved from $27 \%$ to $33 \%$ [24]. The retention of anthocyanins in raspberries $[11,15]$ was improved from $56 \%$ to $76 \%$. Antioxidant activity of carrot [18] deteriorated due to the use of ultrasound. The activity decrease ranged between $13 \%$ to $33 \%$ (depending on US power) compared to simple convective drying.

Ultrasound assistance influenced changes in material texture [5]. Generally streght and Young modulus of material increased due to ultrasound application. Ultrasound dried crisps were more brittle although less crispy that convective dried ones. 
The effect of ultrasound on the material structure was examined using an optical microscope $[4,10]$. The application of ultrasound caused the increase of pore dimentions, the creation of microchannels and disruption of the tissue. These results were confirmed by SEM photographs of convective and ultrasound-convective dried apple [10].

\section{Modeling of US assisted drying}

\subsection{Lumped capacities model}

The lumped capacities model was proposed $[3,25]$ to describe drying kinetics. The final system of coupled ordinary differential equations is as follows:

$$
m_{s} \frac{d X}{d t}=-A_{m} h_{m} \ln \frac{\left.\varphi\right|_{\partial B} p_{v S}\left(T_{m}\right)}{\varphi_{a} p_{v S}\left(T_{a}\right)}
$$

$m_{s} \frac{d}{d t}\left[\left(c_{s}+c_{l} X\right) T_{m}\right]=A_{T} h_{T}\left(T_{a}-T_{m}\right)-A_{m} \ln m \ln \frac{\left.\varphi\right|_{\partial B} p_{v s}\left(T_{m}\right)}{\varphi_{a} p_{v s}\left(T_{a}\right)}+\Delta Q$

where: $A_{m}, A_{T}$ denote surfaces of mass and heat exchange, respectively; $h_{m}, h_{T}$-coefficients of mass and heat exchange, respectively; $\varphi_{a}, \varphi_{\partial B}$ - relative drying air humidity far and near dry material surface, respectively; $p_{v s}$ - saturated vapor partial pressure (temperature dependent); $c_{s}, c_{l}$ - specific heat of a solid and liquid, respectively; $l$ - latent heat of evaporation; $\Delta Q$ - volumetric heat source describing ultrasound absorption.

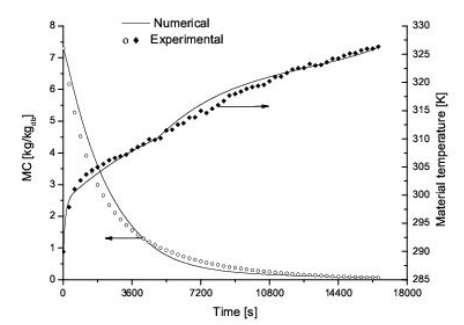

a)

Fig. 2. Drying kinetics of carrots - experimental and numerical results: a) drying curves and temperature of dried material [12]; experimental and model drying rate and "vibration effect", "heating effect" and "synergistic effect" as a function of time

The model was applied to describe ultrasound assisted convective drying in $[3,9,13,14,20,25]$. The model shows very good compatibility with experimental data (Fig. 2a). The results of the process modeling make it possible to analyze the efficiency of ultrasound application. Additional parameters should be specified for this purpose. Drying rate DR expresses the rate of moisture decrease in the material during drying as a function of time and is determined as

$$
\operatorname{DR}(t)=-m_{s} \frac{d X}{d t}=A_{m} h_{m} \ln \frac{\left.\varphi\right|_{\partial B} p_{v s}\left(T_{m}\right)}{\varphi_{a} p_{v s}\left(T_{a}\right)}
$$


The ultrasound assistance improves the drying rate. This is due to three mechanisms associated with the use of ultrasound, namely "vibration effect", "heating effect" and "synergistic effect" [13,22]. The model separates these effects and allows to determine their share in the drying rate (Fig. 2b). The results indicate that the vibrating effect has the largest share in the acceleration of drying. The impact of the other two effects is much smaller.

\subsection{Packed bed drying models and continuous model}

Three models of ultrasound assisted bed drying were proposed [26-28]. All of these models assume lumped capacities of grains and continuous description of the whole bed. Models by Kowalski [26] and Kowalski, Rybicki [27] treat material as not shrinking. Model by Musielak [28] takes into account high shrinkage of grains. All these models describe drying kinetics as well as distributions of moisture content and temperature in the bed.

The continuous model, describing mass and heat transfer in a single body during ultrasound assisted drying is proposed in [7]. The model was developed basing on irreversible thermodynamics. The model allows to calculate and describe the drying kinetics, the distributions of moisture content and temperature in dried body and the shrinkage of the body.

\section{Conclusions}

The paper is a review of research, carried out in Department of Process Engineering, Poznan University of Technology, on the use of ultrasound to intensify osmotic dehydration and drying. In general, it can be concluded that the use of ultrasound significantly accelerates osmosis and convective drying. Thanks to this, energy efficiency of the processes increases. Ultrasonic assistance of microwave drying causes slight acceleration, therefore it is energy inefficient.

In most cases, the use of ultrasound has improved product quality. This is due to the shortening of the drying time and changes in the structure of the dried material.

Mathematical modeling allowed to describe the kinetics of the process. Thanks to this, the magnitude of the impact of individual phenomena on the intensification of drying could be determined.

\section{Acknowledgements}

This work was carried out as a part of research project No 03/32/DSPB/805 sponsored by Poznań University of Technology

\section{References}

[1] Siucińska, K.; Konopacka, D. Application of ultrasounds to modify and improve dried fruid and vegetable tissue: A review. Drying Technology 2014, 32, 1360-1368.

[2] Musielak, G.; Mierzwa, D.; Kroehnke, J.; Food drying enhancement by ultrasound - A review, Trends in Food Science \& Technology 2016, 56, 126-141. 
[3] Kowalski, S.J.; Pawłowski, A. Intensification of apple drying due to ultrasound enhancement, Journal of Food Engineering 2015, 156, 1-9.

[4] Kowalski, S.J.; Mierzwa, D. US-assisted convective drying of biological materials, Drying Technology 2015, 33(13), 1601-1613.

[5] Banaszak, J.; Pawłowski, A. Influence of ultrasound drying on properties of dried apple crisps. In Proceedings of the EuroDrying'2015, Budapest, Hungary, October 2123.2015.

[6] Mierzwa, D.; Kowalski, S.J.; Ultrasound-assisted osmotic dehydration and convective drying of apples: Process kinetics and quality issues, Chemical and Process Engineering 2016, 37 (3), 383-391.

[7] Kowalski, S.J.; Rybicki, A. Ultrasound in wet biological materials subjected to drying, Journal of Food Engineering 2017, 212, 271-282.

[8] Kowalski, S.J.; Mierzwa, D.; Stasiak, M. Ultrasound-assisted convective drying of apples at different process conditions, Drying Technology 2017, 35(8), 939-947.

[9] Kowalski, S.J.; Mierzwa, D.; Szadzińska, J. Highly efficient vegetables drying technologies III: Ultrasound-assisted drying. In Handbook of Drying of Vegetables and Vegetable Products; Zhang, M., Bhandari, B., Fang, Z., Eds.; CRC Press, Taylor \& Francis Group, Boca Raton: London, New York 2017, 81-116.

[10] Rajewska, K.; Mierzwa, D. Influence of ultrasound on structure of the plant tissue. Innovative Food Science and Emerging Technologies 2017, 43, 117-129.

[11] Musielak, G.; Mierzwa, D.; Pawłowski, A.; Rajewska, K.; Szadzińska, J. Hybrid and Non-Stationary Drying - Process Effectiveness and Products Quality. In Practical Aspect of Chemical Engineering; Ochowiak. M, Woziwodzki, S., Doligalski, M., Mitkowski, P.T., Eds.; Springer International Publishing AG: Cham, Switzerland, 2018; 319-338.

[12] Kowalski, S.J.; Szadzińska, J. Convective-intermittent drying of cherries preceded by ultrasonic assisted osmotic dehydration. Chemical Engineering and Processing, Process Intensification, 2014, 82, 65-70.

[13] Szadzińska, J.; Kowalski, S.J.; Stasiak, M. Microwave and ultrasound enhancement of convective drying of strawberries: Experimental and modeling efficiency, International Journal of Heat and Mass Transfer 2016, 103, 1065-1074.

[14] Kowalski, S.J.; Pawłowski, A.; Szadzińska, J.; Łechtańska, J.; Stasiak, M. High power airborne ultrasound assist in combined drying of raspberries. Innovative Food Science and Emerging Technologies 2016, 34, 225-233.

[15] Mierzwa, D.; Szadzińska, J. Non-stationary convective drying of raspberries assisted with microwaves and ultrasound, In Proceedings of EuroDrying'2017 - 6th European Drying Conference, Liege, Belgium, 19-21 June 2017. 
[16] Szadzińska, J.; Łechtańska, J.; Kroehnke, J. Non-stationary convective drying assisted with microwaves and ultrasound. Inżynieria i Aparatura Chemiczna 2016, 55(5), 203204.

[17] Kowalski, S.J.; Szadzińska, J.; Pawłowski, A. Ultrasonic-assisted osmotic dehydration of carrot followed by convective drying with continuous and intermitted heating. Drying Technology 2015, 33(13), 1570-1580.

[18] Kroehnke, J.; Radziejewska-Kubzdela, E.; Musielak, G.; Stasiak, M.; BiegańskaMarecik, R. Ultrasonic-assisted and microwave-assisted convective drying of carrot drying kinetics and quality analysis. In Proceedings of the EuroDrying’2015, Budapest, Hungary, October 21-23.2015.

[19] Mierzwa, D.; Kowalski, S.J.; Kroehnke, J. Hybrid drying of carrot preliminary processed with ultrasonically assisted osmotic dehydration, Food Technology and Biotechnology 2017, 55(2), 197-205.

[20] Kowalski, S.J.; Szadzińska, J.; Pawłowski, A. influence of process parameters variation on hybrid nonstationary drying In Intermittent and Nonstationary Drying Technologies: Principles and Applications. Azharul Karim M., Chung-Lim Law, Eds.; CRC Press, Taylor \& Francis Group, Boca Raton: London, New York 2017; 57-91.

[21] Mierzwa, D.; Musielak, G. Convective drying of carrot - influence of the microwave and ultrasound enhancement, In Proceedings of EuroDrying'2017 - 6th European Drying Conference, Liege, Belgium, 19-21 June 2017.

[22] Szadzińska, J.; Łechtańska, J.; Kowalski, S.J.; Stasiak, M. The effect of high power airborne ultrasound and microwaves on convective drying effectiveness and quality of green pepper, Ultrasonics Sonochemistry 2017, 34, 531-539.

[23] Kroehnke, J.; Musielak, G.; Boratyńska, A. Convective drying of potato assisted by ultrasound, PhD Interdisciplinary Journal 2014, 1, 57-65.

[24] Szadzińska, J. Hybrid-intermittent drying of red beetroot. In Proceedings of EuroDrying’2017 - 6th European Drying Conference, Liege, Belgium, 19-21 June 2017.

[25] Stasiak, M.; Musielak, G.; Kowalski, S.J. Optimization method of evaluation convective heat and mass transfer effective coefficients in drying process. In Proceedings of the EuroDrying'2015, Budapest, Hungary, October 21-23.2015.

[26] Kowalski, S.J. Packed bed drying enhanced with ultrasound. In Proceedings of the EuroDrying'2015, Budapest, Hungary, October 21-23.2015.

[27] Kowalski, S.J.; Rybicki, A. Ultrasonic assisted drying of packed bed. A modeling study. In Proceedings of the EuroDrying’2015, Budapest, Hungary, October 21-23.2015.

[28] Musielak, G. Modeling of heat and mass transfer during ultrasound-assisted drying of a packed bed consisting of highly shrinkable material. Chemical Engineering Research and Design 2018, 129, 25-33. 